\title{
PERFORMANCE EVALUATION OF THERMOGRAPHIC CAMERAS FOR PHOTOGRAMMETRIC MEASUREMENTS
}

\author{
N. Yastikli *, E. Guler \\ YTU, Civil Engineering Faculty, Department of Geomatics Engineering, 34210 Davutpasa Istanbul, Turkey \\ ynaci@yildiz.edu.tr, esragulerytu@gmail.com
}

Commission I, WG I/4, III/4, IC IV/VIII, VII/2

KEY WORDS: Termographic Cameras, Geometric Calibration, Verification, Bundle Block Adjustment, Additional Parameters

\begin{abstract}
:
The aim of this research is the performance evaluation of the termographic cameras for possible use for photogrammetric documentation and deformation analyses caused by moisture and isolation problem of the historical and cultural heritage. To perform geometric calibration of the termographic camera, the 3D test object was designed with 77 control points which were distributed in different depths. For performance evaluation, Flir A320 termographic camera with 320x240 pixels and lens with 18 $\mathrm{mm}$ focal length was used. The Nikon D3X SLR digital camera with 6048 x 4032 pixels and lens with 20 mm focal length was used as reference for comparison. The size of pixel was $25 \mu \mathrm{m}$ for the Flir A320 termographic camera and $6 \mu \mathrm{m}$ for the Nikon D3X SLR digital camera. The digital images of the 3D test object were recorded with the Flir A320 termographic camera and Nikon D3X SLR digital camera and the image coordinate of the control points in the images were measured. The geometric calibration parameters, including the focal length, position of principal points, radial and tangential distortions were determined with introduced additional parameters in bundle block adjustments. The measurement of image coordinates and bundle block adjustments with additional parameters were performed using the PHIDIAS digital photogrammetric system. The bundle block adjustment was repeated with determined calibration parameter for both Flir A320 termographic camera and Nikon D3X SLR digital camera. The obtained standard deviation of measured image coordinates was $9.6 \mu \mathrm{m}$ and $10.5 \mu \mathrm{m}$ for Flir A320 termographic camera and $8.3 \mu \mathrm{m}$ and 7.7 $\mu \mathrm{m}$ for Nikon D3X SLR digital camera. The obtained standard deviation of measured image points in Flir A320 termographic camera images almost same accuracy level with digital camera in comparison with 4 times bigger pixel size. The obtained results from this research, the interior geometry of the termographic cameras and lens distortion was modelled efficiently with proposed approach for geometric calibration.
\end{abstract}

\section{INTRODUCTION}

In the recent years, the digital and thermal infrared cameras have provided powerful tools for photogrammetric documentation of cultural and historical buildings, deformation analysis of buildings and bridges in different investigations. Digital cameras became very popular with their high resolution and automation possibilities in digital photogrammetric documentation. Digital cameras and thermal imaging systems widely used in modern medical, automotive, industrial, architectural, and military applications. (Dominic and Mccafferty, 2007). The use of these thermal imaging systems and cameras is increased for documentation of the historical and cultural heritage, 3D modeling, deformation analysis, restoration and conservation applications (Grinzato et al., 2002).

Thermal imaging systems are the sensor systems, records the temperatures emitted by the objects in infrared region especially in long infrared region $(7-20 \mu \mathrm{m})$. IR thermography transforms the thermal energy, emitted by an object in the infrared band of the electromagnetic spectrum, into a visible image. These sensor systems are enable photogrammetric documentation and deformation analyses caused by moisture and isolation problem in wet areas recorded as historical and cultural heritage which is not possible only use of digital cameras (Rezzi et al., 2007). Infrared (IR) thermography has been extensively used in documentation of cultural heritage, in particular for art work studies (Pelagotti et al., 2007, Ghedini et al., 2003) and for monitoring and conservation of historical buildings (Moropoulo et al., 2001).

The geometric accuracy in photogrammetric documentation, deformation analyses and monitoring studies of historical buildings with termographic cameras mainly related with geometric performance of camera. In this research, the performance evaluation of the termographic cameras is aimed for possible use for photogrammetric documentation and deformation analyses caused by moisture and isolation problem in wet areas which was recorded as historical and cultural heritage. The geometric calibration procedure for termographic camera is presented and tested using the Flir A320 termographic camera. The Nikon D3X SLR digital camera was calibrated and used as reference for comparison.

\section{METHODOLOGY}

Photogrammetry intends to identify of objects shape, size or location recorded with a detection system using the photographs or records in electromagnetic spectrum. For this purpose a large number of measurements have to be performed and orientations parameters have to be determined with known camera geometry (Fraser 1997, Cramer, 2003, Luhmann et al., 2010, Lagüela et al., 2011). In classic photogrammetric approach, camera geometry is expressed with the determined interior orientation parameters. The determination the lens distortion of sensor

\footnotetext{
* Corresponding author. Email address: ynaci@yildiz.edu.tr
} 
system or camera is also important for accuracy of the determined 3D coordinates. In order to obtain threedimensional information from images, at least two images recorded with known camera geometry (interior orientation parameters and lens distortions) from different position in addition to signalized control points (Remondino and Fraser, 2006). These parameters generally determined with geometric calibration in close range photogrammetry with introduced additional parameters to the bundle block adjustment.

Interior orientation parameters consist of focal lenght of photogrammetric cameras $(\mathrm{c})$ and principal point position $\left(\mathrm{x}_{0}\right.$, $\mathrm{y}_{0}$ ). The principal point position in the traditional photogrammetric cameras was defined with photograph coordinate system with the help of the fiducial marks. The lens systems used in cameras was composed with combination use of lenses instead of a single lens. The projection of a points $P$ from $3 \mathrm{D}$ object coordinate system to the $2 \mathrm{D}$ photograph system is not always performed correctly and actual photograph coordinates of point $\mathrm{P}$ is deviated. The difference called lens distortion and has two component radial and tangential distortions.

Geometric calibration is generally performed with introduced additional parameters to bundle adjustment using multi photographs of the test object taken from different points. The mathematical for the bundle adjustments is based on the collinearity equation;

$$
\begin{aligned}
& x-x_{0}=-c \frac{m_{11}\left(X-X_{0}\right)+m_{21}\left(Y-Y_{0}\right)+m_{31}\left(Z-Z_{0}\right)}{\left.m_{13} X-X_{0}\right)+m_{23}\left(Y-Y_{0}\right)+m_{33}\left(Z-Z_{0}\right)}+\Delta x=-c \frac{U}{W}+\Delta x \\
& y-y_{0}=-c \frac{m_{12}\left(X-X_{0}\right)+m_{22}\left(Y-Y_{0}\right)+m_{32}\left(Z-Z_{0}\right)}{m_{13}\left(X-X_{0}\right)+m_{23}\left(Y-Y_{0}\right)+m_{33}\left(Z-Z_{0}\right)}+\Delta y=-c \frac{U}{W}+\Delta y
\end{aligned}
$$

where $\quad \mathrm{x}, \mathrm{y}:$ photograph coordinates

$\mathrm{x}_{0}, \mathrm{y}_{0}:$ principal point photograph coordinates $\mathrm{c}:$ focal length

$\mathrm{X}_{0}, \mathrm{Y}_{0}, \mathrm{Z}_{0}$ : projection centre coordinates in the reference coordinate system

$\mathrm{X}, \mathrm{Y}, \mathrm{Z}$ : object coordinate in reference coordinate systems

$\mathrm{m}_{\mathrm{ij}}=$ rotation matrix elements $(\mathrm{M})$ between to the photograph coordinate system and reference coordinate system

$\Delta \mathrm{x}$ ve $\Delta \mathrm{y}=$ additional parameters

Collinearity equations, is extended to include some systematic errors. Additional parameters used for correction these systematic errors. The most common physical model method developed by Brown in 1971 to eliminate systematic errors. The additional parameters $\Delta x$ ve $\Delta y$ is defined by the expression (McGlone, 2004);

$$
\begin{aligned}
\Delta x & =-x_{0}-\frac{x}{c} \Delta c-\bar{x} A+\bar{y} B+\overline{x r^{2}} K_{1}+\overline{x r^{4}} K_{2}+\overline{x r}^{6} K_{3}+\left(2 x^{-2}+r^{2}\right) P_{1}+2 P_{2} \overline{x y} \\
\Delta y & =-y_{0}-\frac{\bar{y}}{c} \Delta c-\bar{x} B+\bar{y} r^{2} K_{1}+\bar{y} r^{4} K_{2}+\overline{y r} r^{6} K_{3}+2 P_{1} \overline{x y}+\left(2 y^{-2}+r^{2}\right) P_{2}
\end{aligned}
$$

where $\bar{x}, \bar{y}$ : photograph coordinates referred to the principal points

$r$ : radial distance

$\mathrm{Ki}$ : radial distortion coefficients

P1 , P2 : tangential distortion parameters
The photograph coordinates referred to the principal points, radial distortion $\Delta \mathrm{r}$ are defined by the expression;

$$
\begin{aligned}
& \bar{x}=x-x_{0} ; \bar{y}=y-y_{0} ; r=\sqrt{\bar{x}^{2}+\bar{y}^{2}} \\
& \Delta \mathrm{r}=\mathrm{K}_{1} \mathrm{r}^{3}+\mathrm{K}_{2} \mathrm{r}^{5}+\mathrm{K}_{3} \mathrm{r}^{7}
\end{aligned}
$$

The introduced additional parameters in bundle block adjustment are estimated with measured coordinate of tie point and control points in all photographs. The coordinate of control points should be precisely known and control points should distributed different depth and different location. In general, 3D test object is used for geometric calibration process. The 3D test object is important for accurate estimation of interior orientation parameters and lens distortions.

\section{EXPERIMENT}

To perform, precise geometric calibrations of termographic cameras, 3D test object which has 77 control points distributed in different depth and location was designed (Figure 1). The location of control points were designed so that not covers other control points when the images recorded from different position and angles. In other words, the main aimed was measure maximum number of control point on images recorded from different positions. The 3D design and modelling has been performed by using Auotocad software. As can be seen in Figure 1, the distance between the red, green and blue planes approximately $70 \mathrm{~cm}$ which supplied control points distributed three different depths. The designed 3D test object was manufactured from iron profile and special marks placed on the control points which produced by plastics. The coordinates of control points were measured with reflectorless total station with high accuracy.

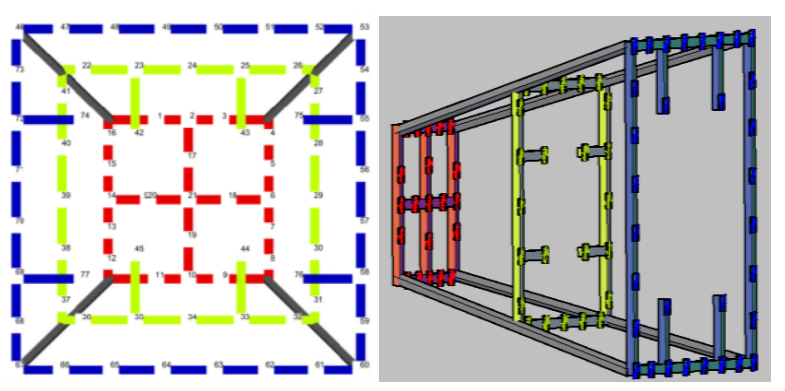

Figure 1. 3D test object

For performance evaluation, Flir A320 termographic camera with spectral range is 7.5-13 $\mu \mathrm{m}$ was used. The Nikon D3X SLR digital camera was used as reference for comparison (Figure 2). The technical details of the used camera can be seen in Table 1.

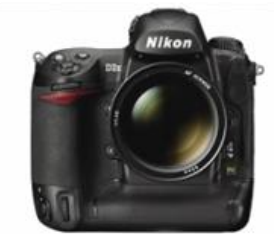

(a)

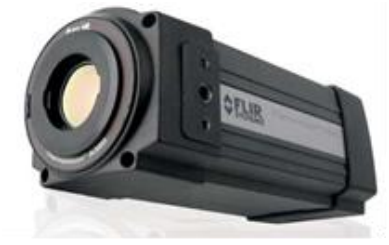

(b)
Figure 2. Nikon D3X SLR digital camera (a) and Flir A320 thermal camera (b) 
International Archives of the Photogrammetry, Remote Sensing and Spatial Information Sciences, Volume XL-1/W1, ISPRS Hannover Workshop 2013, 21 - 24 May 2013, Hannover, Germany

\begin{tabular}{|l|c|c|}
\hline Properties & Digital Camera & Thermal Camera \\
\hline Camera Model & Nikon D3X & Flir A320 \\
\hline Piksel number & $\begin{array}{l}6048 \mathrm{x} \\
4032\end{array}$ & $320 \times 240$ \\
\hline Piksel Size & $6 \mu \mathrm{m}$ & $25 \mu \mathrm{m}$ \\
\hline Focal Length & $20 \mathrm{~mm}$ & $18 \mathrm{~mm}$ \\
\hline Thermal Resolution & - & $\pm 2 \mathrm{C}^{\mathbf{o}}$ \\
\hline
\end{tabular}

Table 1. Technical properties of cameras

The digital images of the 3D test object were recorded with Flir A320 termographic camera and Nikon D3X SLR digital camera from different positions and orientation angles $\left(0^{\circ}, 90^{\circ} 180^{\circ}\right.$ and $270^{\circ}$ ) (Figure 3).

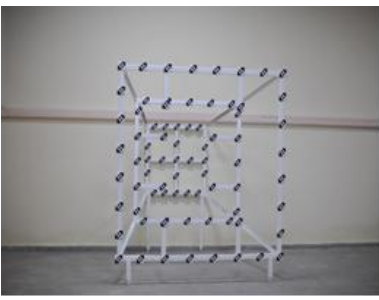

(a)

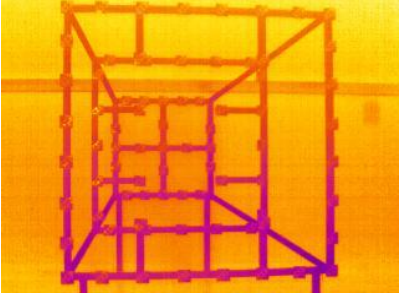

(b)
Figure 3. The image recorded with theNikon D3X SLR digital camera (a) and Flir A320 thermal camera (b)

The location of the principal point was set the centre of images for both digital and termographic camera and photograph coordinate system was defined each recorded images. The photograph coordinates of the control points were measured manually on digital and termographic images. The PHIDIAS software was used for coordinate measurement and bundle adjustment which developed by PHOCAD. Figure 4 shows the photograph coordinate measurement of the control points on images recorded with digital camera from different positions. The bundle block adjustment was performed first with given focal length (see Table 1), principal point location (centre of images) and blunders were eliminated. At the second stage of bundle block adjustment, additional parameters which consist of interior orientation parameters $\left(\Delta \mathrm{x}_{0}, \Delta \mathrm{y}_{0}, \Delta \mathrm{c}\right)$, radial distortion $(\mathrm{K} 1, \mathrm{~K} 2, \mathrm{~K} 3)$ and tangential distortion $(\mathrm{P} 1, \mathrm{P} 2)$ parameters were included.
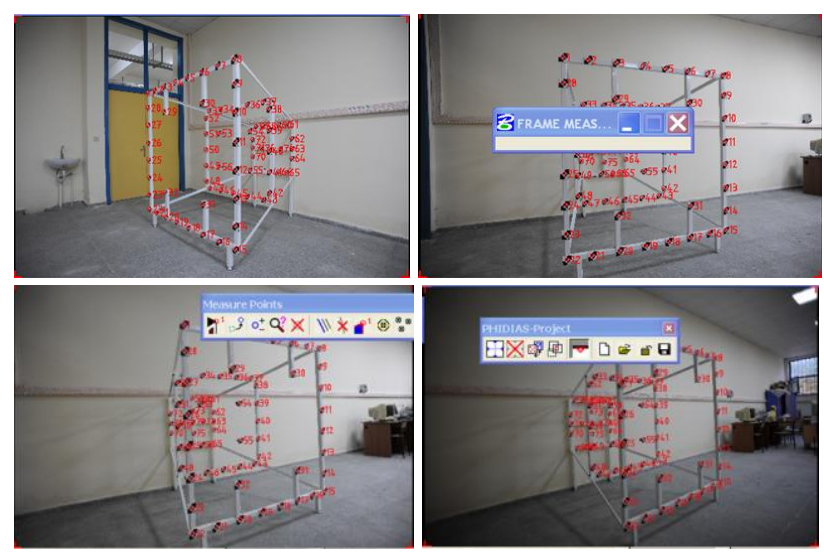

Figure 4. Control points measurements on the 3D test object with Nikon D3X SLR digital camera
The determined geometric calibration parameters with bundle block adjustment for the Flir A320 termographic camera and the Nikon D3X SLR digital camera were given in Table 2 and Table 3.

\begin{tabular}{|c|c|c|}
\hline $\begin{array}{c}\text { Additional } \\
\text { Parameters }\end{array}$ & Parameter & $\begin{array}{c}\text { Standard } \\
\text { Deviation }\end{array}$ \\
\hline Focal length, c $(\mathrm{mm})$ & 17.2262 & 0.1288 \\
\hline Principal point $\mathrm{x}_{0}(\mathrm{~mm})$ & 0.2883 & 0.0512 \\
\hline Principal point $\mathrm{y}_{0}(\mathrm{~mm})$ & -0.1995 & 0.0656 \\
\hline Radial distortion $\mathrm{K}_{1}$ & $-30.6381 * 10^{-4}$ & 4.6329 \\
\hline Radial distortion $\mathrm{K}_{2}$ & $2599.4545 * 10^{-7}$ & 493.9109 \\
\hline Radial distortion $\mathrm{K}_{3}$ & $-98791.5437 * 10^{-10}$ & 16416.952 \\
\hline Tangential distortion $\mathrm{P}_{1}$ & $-22.6353 * 10^{-5}$ & 4.6768 \\
\hline Tangential distortion $\mathrm{P}_{2}$ & $28.1114 * 10^{-5}$ & 4.8051 \\
\hline
\end{tabular}

Table 2. Flir A320 termographic cameras geometric calibration parameters

\begin{tabular}{|c|c|c|}
\hline $\begin{array}{c}\text { Additional } \\
\text { Parameters }\end{array}$ & Parameter & $\begin{array}{l}\text { Standard } \\
\text { Deviation }\end{array}$ \\
\hline Focal length, $\mathrm{c}(\mathrm{mm})$ & 19.7582 & 0.0293 \\
\hline Principal point $\mathrm{x}_{0}(\mathrm{~mm})$ & -0.0293 & 0.0102 \\
\hline Principal point $\mathrm{y}_{0}(\mathrm{~mm})$ & -0.0955 & 0.0104 \\
\hline Radial distortion $\mathrm{K}_{1}$ & $-2.8036 * 10-4$ & 0.0267 \\
\hline Radial distortion $\mathrm{K}_{2}$ & $5.6921 * 10-7$ & 0.2301 \\
\hline Radial distortion $\mathrm{K}_{3}$ & $-2.7187 * 10-10$ & 0.5545 \\
\hline Tangential distortion $\mathrm{P}_{1}$ & $-4.3235 * 10-5$ & 0.6193 \\
\hline Tangential distortion $\mathrm{P}_{2}$ & $-7.2408 * 10-5$ & 0.6136 \\
\hline
\end{tabular}

Table 3. Nikon D3X SLR digital cameras geometric calibration parameters .

The Flir A320 thermal cameras focal length was determined $17.2262 \mathrm{~mm}$ and principle points location ( $\mathrm{x}$ o, $\mathrm{y}^{\circ}$ ) was determined $0.2883 \mathrm{~mm},-0.1995 \mathrm{~mm}$. The Nikon D3X SLR digital cameras focal length was determined $19.7582 \mathrm{~mm}$ and principle points location ( $\mathrm{x}_{\mathrm{o}}, \mathrm{y}_{\mathrm{o}}$ ) was determined $0.0293 \mathrm{~mm}$, $-0.0955 \mathrm{~mm}$. The correction for the focal length and principal point location and radial and tangential distortion parameters bigger for Flir A320 termographic camera in comparison to the The Nikon D3X SLR digital cameras as expected (see Table 2 and Table 3). The results of the geometric calibration show that, the termographic camera yield high distortion value and large shift of principal points. When compare the performance of 
termographic and digital camera, the pixel size should also be taken into account since the pixel size was $25 \mu \mathrm{m}$ for termographic camera and $6 \mu \mathrm{m}$ for digital camera.

The bundle block adjustment were repeated with determined geometric calibration parameters for both Flir A320 termographic camera and Nikon D3X SLR digital camera. The obtained results of the measured image coordinates were given in Table 4.

\begin{tabular}{|l|c|c|}
\hline Camera & $\sigma_{\mathrm{x}}(\mathrm{mm})$ & $\sigma_{\mathrm{y}}(\mathrm{mm})$ \\
\hline $\begin{array}{l}\text { Nikon D3X SLR } \\
\text { Digital camera }\end{array}$ & 0.00830 & 0.00770 \\
\hline $\begin{array}{l}\text { Flir A320 Thermal } \\
\text { camera }\end{array}$ & 0.00963 & 0.01054 \\
\hline
\end{tabular}

Table 4. The standard deviation of the measured image coordinates.

The obtained standard deviation of measured image points in Flir A320 termographic camera images almost same accuracy level with digital camera in comparison with 4 times bigger pixel size. These results show that, interior geometry of the termographic cameras and lens distortion modelled efficiently with proposed approach for geometric calibration.

\section{CONCLUSIONS}

In this study, the workflow for the performance evaluation of the termographic and digital cameras is presented for possible use for determination of 3D geometric locations of the historical and cultural heritage buildings in photogrammetric documentation and deformation analyses caused by moisture and isolation problem of the historical and cultural heritage. The 3D test object was designed and manufactured for the geometric. The geometric calibration parameter were determined with introduced additional parameters into the bundle block adjustments for interior orientation parameters $\left(\mathrm{x}_{0}\right.$, $\left.\mathrm{y}_{0}, \mathrm{c}\right)$, radial distortion parameters $(\mathrm{K} 1, \mathrm{~K} 2, \mathrm{~K} 3)$ and tangential distortion parameters (P1, P2) for both Flir A320 termographic camera and The Nikon D3X SLR digital camera. The results of the geometric calibration show that, the termographic camera yield high distortion value and large shift of principal points. When compare the performance of termographic and digital camera, the pixel should also be taken into account since the pixel size was $25 \mu \mathrm{m}$ for termographic camera and $6 \mu \mathrm{m}$ for digital camera.

The bundle block adjustments were repeated with determined geometric calibration parameters for both Flir A320 termographic camera and Nikon D3X SLR digital camera. The obtained standard deviation of measured image coordinates was $9.6 \mu \mathrm{m}$ and $10.5 \mu \mathrm{m}$ for Flir A320 termographic camera and 8.3 $\mu \mathrm{m}$ and $7.7 \mu \mathrm{m}$ for Nikon D3X SLR digital camera. The obtained standard deviation of measured image points in Flir A320 termographic camera images almost same accuracy level with digital camera in comparison with 4 times bigger pixel size. These results showed that, interior geometry of the termographic cameras and lens distortion was modelled efficiently with proposed approach for geometric calibration.

The obtained results from this research showed that, if the interior geometry of the termographic cameras and lens distortion modelled efficiently with $3 \mathrm{D}$ test object, these cameras can be used for photogrammetric documentation and deformation analyses caused by moisture and isolation problem of the historical and cultural heritage accept for the defining the object border because of small pixel size.

\section{REFERANCES}

Brown, D.C., 1971. Close-range camera calibration, Photogrammetric Engineering, 37(8), pp.855-866.

Clark M.R., McCann D.M., Forde M.C., 2003, Application of infrared thermography to the non-destructive testing of concrete and masonry bridges, UK, NDT\&E International, 36, pp. 265275.

Cramer, M., 2003. EuroSDR Project Digital Camera Calibration, Presentation of Project Proposal, 103rd EuroSDR Science and Steering Committee Meetings, München, Germany.

Cramer M., 2003, Digital camera self-calibration, 2003, ISPRS International Journal of Photogrammetry and Remote Sensing, 52:149-159.

Fraser C.S., 1997, Digital Camera Self- Calibration, Australia, ISPRS Journal of Photogrammetry \& Remote Sensing, pp. 149159.

Ghedini N. Sabbioni C., Pantani M.,2003, Thermal analysis in cultural heritage safeguard: an application, Bologna, Italy Thermochimica Acta, pp. 105-113.

Grinzato, E., Bison, P.G., Marinetti, S., 2002. Monitoring of Ancient Buildings by The Thermal Method, Italy, Journal of Cultural Heritage, 3, pp.21-29.

Grinzato E., Peron F., Strada M., 1999. Moisture monitoring of historical buildings by long-period temperature measurements. Thermosense XXI, SPIE 3700, pp. 471-482.

Grinzato E., 2012, IR Thermography Applied to the Cultural Heritage Conservation, 18th World Conference on Nondestructive Testing, Durban, South Africa.

Honkavaara E., Ahokas E., Hayyppa J., Kaartinen H., Kuittinen R., Markelin L., Nurminen K., 2006, Geometric test field calibration of digital photogrammetric sensors, Finland. ISPRS Journal of Photogrammetry \& Remote Sensing, 65, pp.387399.

Lerma J.L., Mileto C. , Vegas F. , Cabrelles M., 2007. Visible And Thermal IR Documentation of A Masonry Brickwork Building, XXI International CIPA Symposium, Athens, Greece.

Lagüela, S., González-Jorge, H., Armesto J., Arias P., 2011, Calibration And Verification Of Thermographic Cameras For Geometric Measurements, Infrared Physics \& Technology, 54, Spain. pp. 92-99.

Lucchese, L.,2005. Geometric calibration of digital cameras through multi-view rectification, USA, Image and Vision Computing, 23 , pp. 517-539.

Lichti D. D., Kim C., Jamtsho S., 2010. An Integrated Bundle Adjustment Approach to Range Camera Geometric SelfCalibration, ISPRS Journal of Photogrammetry and Remote Sensing, 65, pp. 360_368. 
International Archives of the Photogrammetry, Remote Sensing and Spatial Information Sciences, Volume XL-1/W1, ISPRS Hannover Workshop 2013, 21 - 24 May 2013, Hannover, Germany

Luhmann, T., Ohm, J., Piechel, J., Roelfs, T., 2010. Geometric Calıbration Of Thermographic Cameras. Commission $V, W G$ $V / 5$, Germany.

Mccafferty, D. J. , 2007. The Value Of İnfrared Thermography For Research On Mammals; Previous Applications And Future Directions, Mammal Rev., Volume 37, No. 3, pp. 207-223.

McGlone, J. C., 2004. Manuel of Photogrammery, Fifth Edition, ASPRS, ISBN 1-57083-071-1, pp. 652, 653.

Meola C., Di Maio R., Roberti N., Carlomagno G.M. ,2005. Application of Infrared Termography and Geophysical Methods for Defect Detection in Architectural Structures, Engineering Failure Analysis, 12, pp. 875-892.

Peipe J., Tecklenburg W., Photogrammetrıc Camera Calıbratıon Software-A Comparison, Commission $V, W G$ V/l.

Remondino, F., Fraser, C., 2006. Digital Camera Calibration Methods: Considerations And Comparisons, ISPRS Commission V Symposium, Commission V, WG V/1.

Rizzi, A., Voltolini, F., Girardi, S., Gonzo, L., Remondino, F., 2007, Digital Preservation, Documentation And Analysis Of Paintings, Monuments And Large Cultural Heritage With Infrared Technology, XXI International CIPA Symposium, Greece. 